\title{
Application of Color Metallography to Study the Microstructure of Friction Stir-Welded Dual-Phase Brass Using Various Etchants
}

\author{
I. Dinaharan ${ }^{1}$ (I) E. T. Akinlabi ${ }^{1}$
}

Received: 17 December 2016/Revised: 1 February 2017/Accepted: 13 February 2017/Published online: 23 February 2017

(C) Springer Science+Business Media New York and ASM International 2017

\begin{abstract}
Brass is difficult to join using conventional fusion welding processes due to the loss of zinc during fusion. The relatively new friction stir welding (FSW) is a promising process to join brass without loss of zinc. The aim of the present work is to join 6-mm-thick $\mathrm{Cu}-38.55 \mathrm{Zn}$ brass using FSW and investigate the microstructure using color metallography. Two color etchants, namely Beraha 13a and Beraha 12a, were used to reveal the microstructure. The welded joints showed various zones due to the application of frictional heat and severe plastic deformation. The microstructure of heat affected zone was identical to that of base metal. The weld zone consisted of fine equiaxed grains due to dynamic recrystallization. Partial crystallization was observed along the thickness direction in the weld zone. The micrographs obtained using Beraha 12a etchant were better to that of Beraha 13a etchant.
\end{abstract}

Keywords Brass $\cdot$ Friction stir welding $\cdot$ Color metallography $\cdot$ Microstructure

I. Dinaharan

dinaweld2009@gmail.com

E. T. Akinlabi

etakinlabi@uj.ac.za

1 Department of Mechanical Engineering Science, University of Johannesburg, Auckland Park Kingsway Campus, Johannesburg 2006, South Africa

\section{Introduction}

$\mathrm{Cu}-\mathrm{Zn}$ alloys (Brass) are extensively utilized as an industrial material due to excellent characteristics such as high corrosion resistance, high electrical and thermal conductivity, non-magnetism, capacity for high levels of plastic deformation and machinability [1]. It is extremely difficult to join brass using conventional fusion welding processes [2]. The high temperature causes evaporation of zinc from brass which creates pores in the welded structure [2]. Thus, the loss of zinc results in poor physical and chemical properties of joints [2]. Friction stir welding (FSW) is a solid-state welding technique which minimizes the aforementioned problems in joining brass. A non-consumable rotating tool is driven into the abutting edges and traversed along the interface. The frictional heat plasticizes the material and is consolidated at the back of the tool due to the force applied along the tool rotating axis [3].

Some studies on joining of brass using FSW were reported in the literature [4-10]. Park et al. [4] joined 2-mm-thick $\mathrm{Cu}-40 \mathrm{Zn}$ brass and reported the microstructural evolution. Meran [5] joined 3-mm-thick $\mathrm{Cu}-30 \mathrm{Zn}$ brass and analyzed the FSW process capability to join brass. Çam et al. [6] joined 3-mm-thick $\mathrm{Cu}-37 \mathrm{Zn}$ brass and evaluated the joint microstructure and properties. Moghaddam et al. [7] joined 5-mm-thick $\mathrm{Cu}-30 \mathrm{Zn}$ brass and investigated the effect of traverse speed. Emamikhah et al. [8] joined 3-mm-thick $\mathrm{Cu}-40 \mathrm{Zn}$ brass and explored the effect of tool pin profile on joint microstructure and strength. $\mathrm{Xu}$ et al. [9] joined 2-mm-thick $\mathrm{Cu}-30 \mathrm{Zn}$ brass and estimated the effect of rapid cooling on microstructure. Emami and Saeid [10] joined 2-mm-thick $\mathrm{Cu}-33.8 \mathrm{Zn}$ brass and investigated the effect of rotational speed and welding speed on joint integrity. Although several previous studies have proven that brass can be effectively joined using the 
Table 1 Chemical composition of brass

\begin{tabular}{llllllllll}
\hline Material & $\mathrm{Zn}$ & $\mathrm{Pb}$ & $\mathrm{Sn}$ & $\mathrm{Ni}$ & $\mathrm{Fe}$ & $\mathrm{S}$ & $\mathrm{Al}$ & $\mathrm{P}$ & $\mathrm{Cu}$ \\
\hline Brass & 38.55 & 3.44 & 0.30 & 0.20 & 0.19 & - & - & - & Balance \\
\hline
\end{tabular}

FSW process, there is limited work on detailed characterization of the resulting weldment.

A short literature survey revealed that many investigators used black and white etchants consisting of various amounts of iron (III) chloride and hydrochloric acid in water. The optical micrographs were poor in quality in many cases. Color metallography helps to visualize various phases in pure metals and alloys easily. It is more sensitive to segregation, grain orientation and stress state compared to conventional black and white metallography [11]. Color microstructures can be produced by a number of techniques that depend on film formation and interference effects. These films can be formed thermally or by chemical deposition or by vapor deposition. Among those methods, chemical deposition, i.e., tint etching, is simple and convenient [12].

The objective of the present work is to join 6-mm-thick dual-phase brass plates using FSW and study the microstructure using two color etchants which are widely applied for pure copper and its alloys. Most of the literature [4-6, 8-10] used brass plates of thickness $3 \mathrm{~mm}$ and lower. In this work, $6 \mathrm{~mm}$ thickness was chosen to observe the effect of thickness on the nature of recrystallization process.

\section{Experimental Procedure}

Brass plates of size $100 \times 50 \times 6 \mathrm{~mm}$ were used in this research work. The composition of as received brass is furnished in Table 1 . The butt welding of brass plates was accomplished semiautomatically using a FSW machine (M/s RV Machine Tools). A tool made of hot working steel H13 as depicted in Fig. 1 was used for welding. The tool was double tempered to increase its hot working behavior. The tool has a shoulder diameter of $24 \mathrm{~mm}$, pin diameter of $6 \mathrm{~mm}$ and pin length of $5.7 \mathrm{~mm}$. The tool pin has a straight cylindrical profile. The joints were fabricated at a tool rotational speed of $1200 \mathrm{rpm}$, welding speed of $40 \mathrm{~mm} /$ min and axial force of $10 \mathrm{kN}$. The parameters were chosen based on several trail runs to produce a defect free weld. An example of a friction stir-welded brass plate is shown in Fig. 2. Specimens were machined from the welded plates to carry out microstructural characterization. The specimens were prepared as per standard metallographic procedure. The specimens were initially polished using various grits $(220,320,400,600,800,1000$ and 1200) of

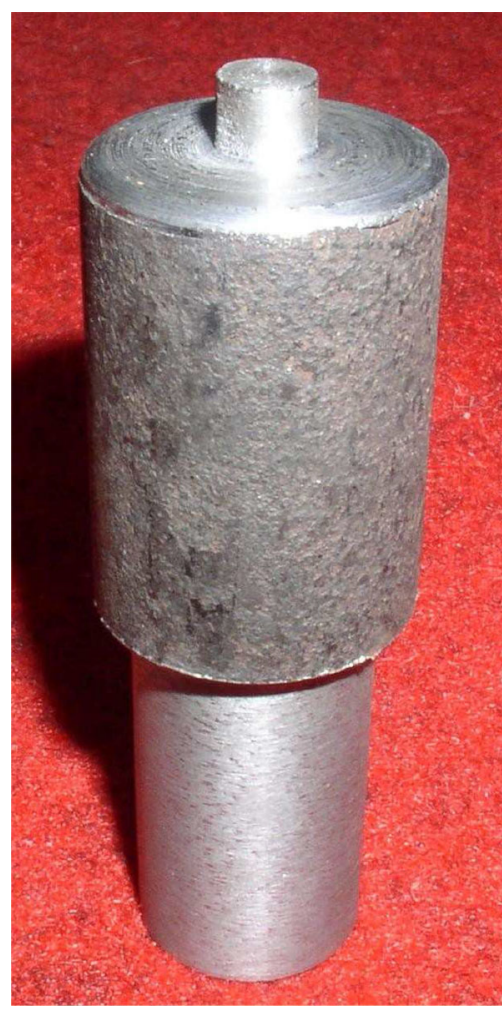

Fig. 1 Friction stir welding tool

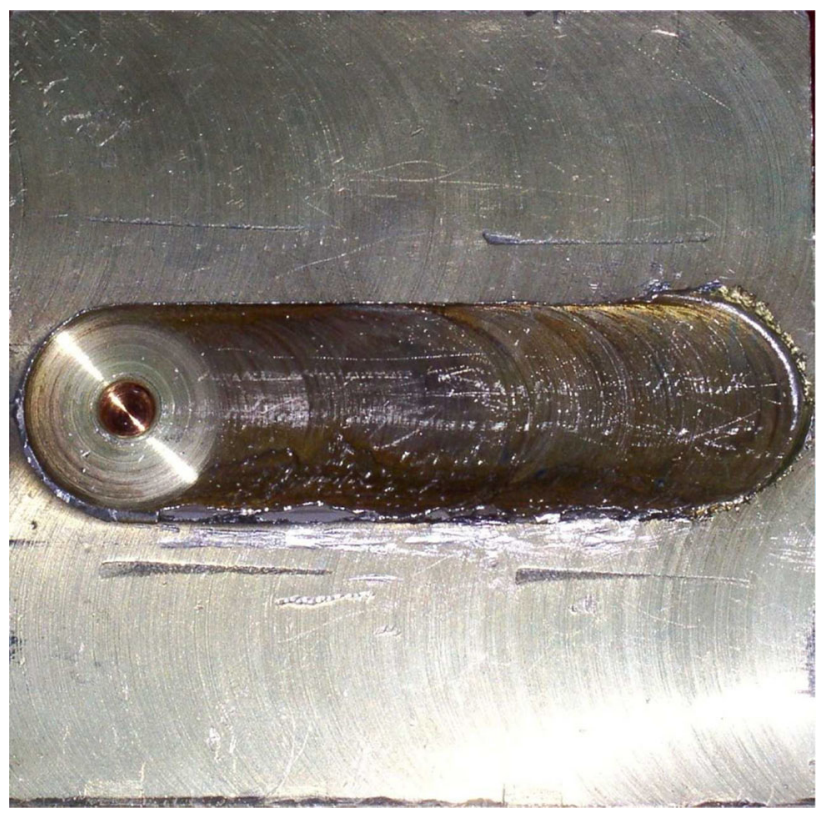

Fig. 2 Example of friction stir-welded brass plates

silicon carbide grinding papers. Subsequently, the specimens were fine polished using colloidal silica $(<3 \mu \mathrm{m})$ and alumina $(<3 \mu \mathrm{m})$ suspension. The polished specimens were etched using various color etchants as given in Table 2 [13]. Microstructure was observed using an optical microscope. 
Table 2 Etchants for brass

\begin{tabular}{lllll}
\hline S. No. & Etchant name & Composition & References \\
\hline 1 & Beraha 13a & $20 \mathrm{~g}$ chromic acid, $2 \mathrm{~g}$ sodium sulfate and $1.7 \mathrm{ml} \mathrm{HCl} \mathrm{(35 \% )} \mathrm{in} 100 \mathrm{ml}$ distilled water & {$[13]$} \\
2 & Beraha 12a & $24 \mathrm{~g}$ sodium thiosulphate, $2.4 \mathrm{~g}$ lead acetate, $3 \mathrm{~g}$ citric acid in $100 \mathrm{ml}$ distilled water & {$[13]$} \\
3 & Ferric chloride solution & $2-10 \mathrm{~g}$ iron(III)chloride, $2-15 \mathrm{ml}$ hydrochloric acid in $50-100 \mathrm{ml}$ distilled water & [4-10] \\
\hline
\end{tabular}

\section{Results and Discussion}

\section{Effect of Welding}

6-mm-thick $\mathrm{Cu}-38.55 \mathrm{Zn}$ brass was successfully welded using FSW. The upper surface appearance on the welded plate is seen in Fig. 2. There are no cracks or depressions on the upper surface. It indicates successful deformation of brass and flow of material from advancing side to retreating side. Absence of surface defects can be attributed to proper consolidation of plasticized brass at the back of the tool during welding. There is little or no flash appeared on the retreating side.

The microstructure of the welded brass revealed the formation of different zones as depicted in Figs. 3 and 4. The grain size was varied from the weld zone toward base metal. Various regions across the joint line experience different degrees of plasticization and frictional heat which result in the formation of different zones. These zones are, namely base metal (BM), heat affected zone (HAZ), thermo-mechanically affected zone (TMAZ) and stir zone (SZ). The microstructure of base metal (Figs. 3a, 4a) shows the presence of two phases. The brass used in this research work contained high amount of zinc $(38.55 \%)$ which promotes the dual-phase structure. The phases are known as alpha $(\alpha)$ and beta $(\beta)$. The microstructure of the HAZ (Figs. 3b, 4b) is not clearly distinguishable from base metal. There is no major change in the composition of alpha and beta phases. The frictional heat generated did not cause any transformation of beta phase into alpha phase. In other words, it can be said that HAZ is absent or negligible in the present research work. Similar observations were reported by some researchers $[4,6,8,10]$. Nevertheless, Xie et al. [14] noticed a clear formation of HAZ in FSW of dual-phase 5-mm-thick brass plates. He attributed the formation of HAZ due to the transformation of beta phase into alpha phase. The frictional heat generated under the experimental conditions of Xie et al. induced phase transformation and formed HAZ. Hence, the absence of HAZ in this work can be attributed to insufficient frictional heat input condition under the chosen set of process parameters to trigger phase transformation.

The microstructure of the transition zone is seen in Figs. $3 \mathrm{c}$ and $4 \mathrm{c}$. A drastic change in microstructure from
HAZ to SZ is identified in this micrograph. A narrow TMAZ is visible between the SZ and HAZ. Grains in this region are irregularly elongated, and their orientation is different from the base metal. The equiaxed grains in the base metal are elongated due to shear deformation and tilted along the thickness direction. A closer examination of TMAZ revealed a mixture of small and larger size grains. The large variation in grain size can be caused by the following factors; (a) the tool pin causes shear deformation which induces thermal effects; (b) severe plastic deformation causes nucleation of new and fresh grains and (c) occurrence of dynamic crystallization phenomena.

The microstructure of the weld zone (Figs. 3d, 4d) displays very fine equiaxed grains. It is interesting to observe that the dual phase of brass is retained even after welding. This observation suggests that the zinc in the brass is preserved during welding. A loss in zinc would have caused the dual phase to disappear. FSW is a suitable technique to weld dual-phase high zinc brass. The grain size in the weld zone is refined considerably compared to base metal. It is well reported in the literature that the cause of the fine grains in the weld zone in FSW is dynamic recrystallization. Dynamic recrystallization is one of the key phenomena in metallurgy which governs the size of grains [3]. Dynamic recrystallization is commonly found in metals which undergo hot working processes. The severe plastic deformation and friction heating during FSW results in the formation of recrystallized fine grain structure. Dynamic recrystallization takes place either by continuous extended recovery processes through extinction and rearrangement of dislocations or by a discontinuous formation of relatively dislocation-free grains through recrystallization [10]. The mechanism of operation is depended upon the strain rate history in addition to stacking fault energy of the material. Higher strain rate and stresses in a material lead to discontinuous recrystallization. Materials which have low stacking fault energy often experiences discontinuous dynamic recrystallization because the dissociation of the dislocations causes the recovery more complicated [10]. On the other hand, materials which have high stacking fault energy undergo continuous dynamic recrystallization. Since the stacking fault energy of brass is lower as compared to copper, it can be stated that it experiences a discontinuous dynamic recrystallization. 
Fig. 3 Optical micrographs of friction stir-welded brass using Beraha 13a etchant: (a) base metal, (b) heat affected zone, (c) transition zone and (d) weld zone
Fig. 4 Optical micrographs of friction stir-welded brass using Beraha 12a etchant: (a) base metal, (b) heat affected zone, (c) transition zone and (d) weld zone
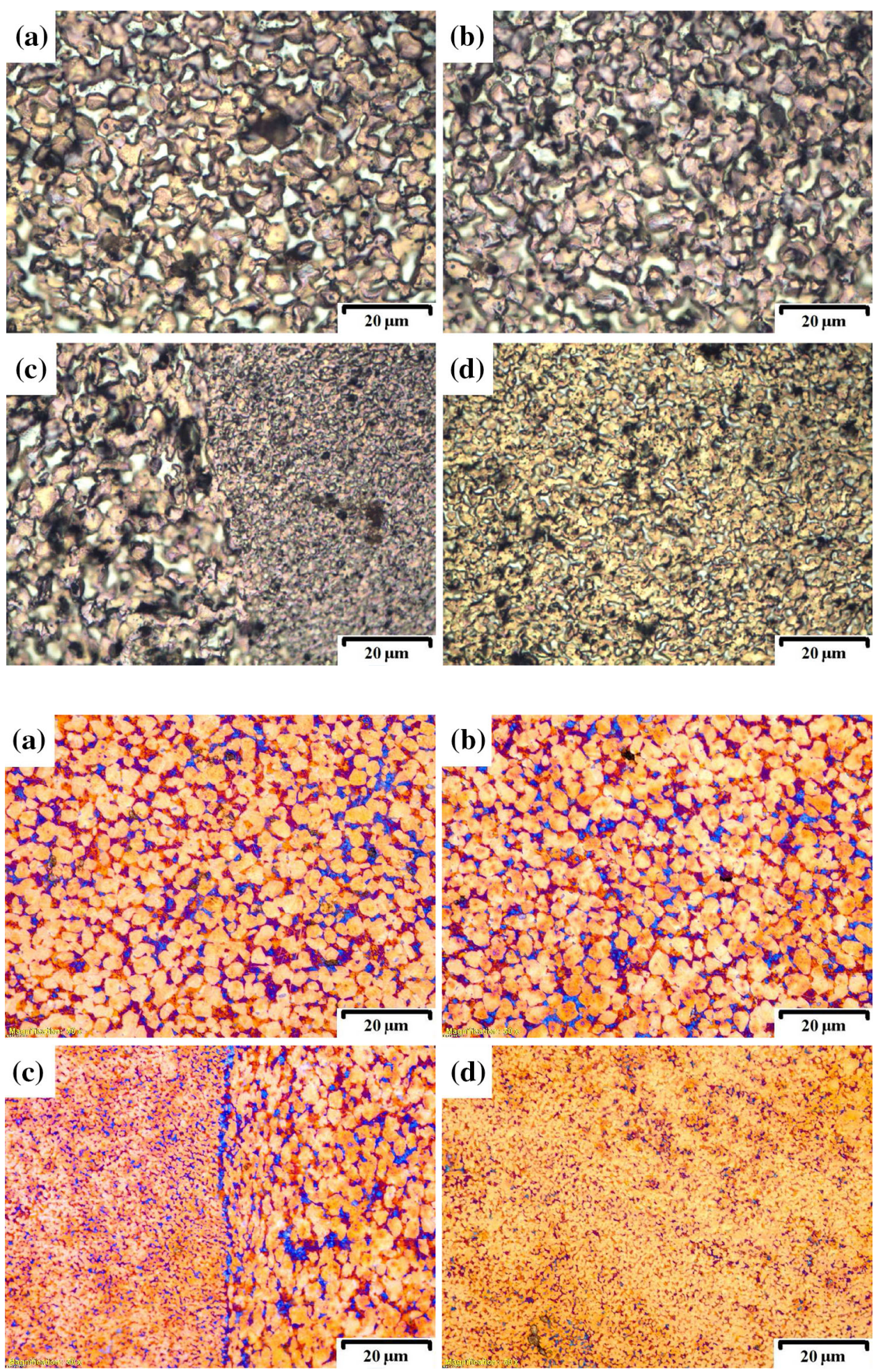

Figure 5 represents the optical micrographs of the stir zone at various thicknesses of the joint. It is interesting to observe that the microstructure is not homogenous. A heterogeneous microstructure was observed. Generally, a homogenized fully recrystallized microstructure is observed in FSW of aluminum and magnesium alloys as well as in pure copper [3]. Early researchers who investigated FSW of brass with thicknesses 2 and $3 \mathrm{~mm}$ reported a homogenous microstructure in the weld zone $[4,5,8]$. However, this observation agrees to the findings of Xie et al. [15] who reported a heterogeneous microstructure in FSW of 5-mm-thick $\mathrm{Cu}-38 \mathrm{Zn}$ brass. The variation of the 
Fig. 5 Optical micrographs of friction stir-welded brass using Beraha 12a etchant at X mm from the shoulder region:

(a) $1 \mathrm{~mm}$, (b) $3 \mathrm{~mm}$, (c) $4 \mathrm{~mm}$, (d) $4.5 \mathrm{~mm}$, (e) $5 \mathrm{~mm}$ and (f) $5.5 \mathrm{~mm}$
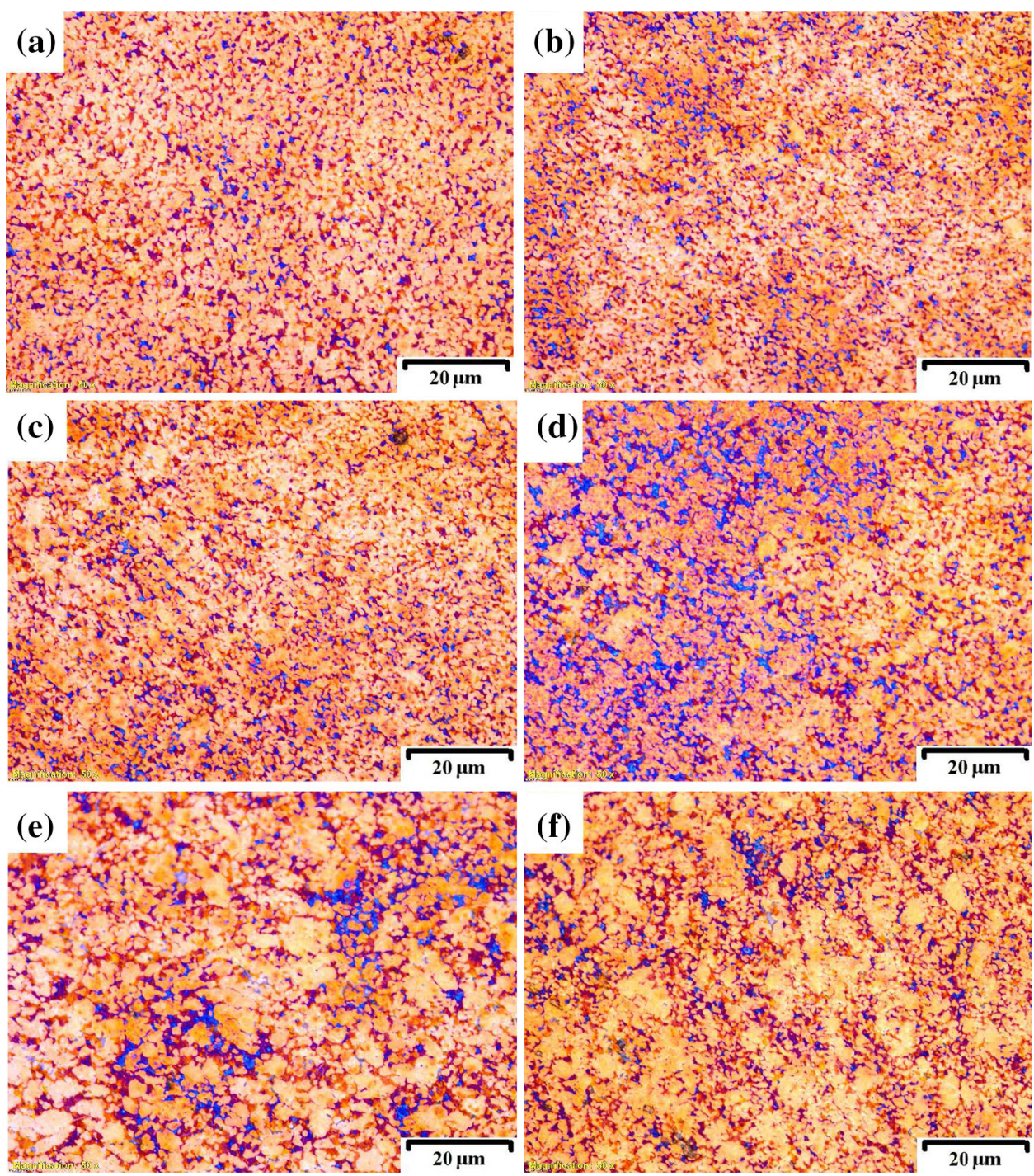

recrystallized microstructure along the thickness direction is clearly seen in Fig. 5. The microstructure up to $4 \mathrm{~mm}$ thickness is composed of fully recrystallized grains formed in the process of dynamic recrystallization. Afterward, the microstructure is a mixture of fully recrystallized grains and coarse non-recrystallized deformed grains. A comparison of the present work and earlier reports suggests that the thickness of the brass plates is a factor to achieve homogenous microstructure. The thickness of the brass plates in this work is $6 \mathrm{~mm}$. Brass possesses high thermal conductivity. The higher plate thickness and thermal conductivity prevent a homogenous flow of plasticized brass throughout the weld zone due to temperature and strain gradient. The upper half which is closer to shoulder region experiences intense plastic deformation due to higher shear rate. Hence, the grains were fully recrystallized. Secondly, the beta phase has an influence on the degree of plasticization of brass. The beta phase is in high volume fraction due to high amount of zinc which causes dual phase. The harder beta phase has a tendency to oppose plastic flow during welding and affects the degree of recrystallization. A comparison of Figs. 5 and 4a reveals that the fraction of beta phase has increased (10\%) subsequent to FSW. This observation suggests that part of alpha phase was transformed into beta phase during FSW. The transformed beta phase is retained in the weld zone due to faster cooling rate. The pinning effect of the beta phase particles causes insufficient plastic deformation and prevents the completion of dynamic recrystallization.

\section{Effect of Color Etchants}

The variation in color microstructure of the welded brass using color etchants Beraha 13a and 12a is, respectively, shown in Figs. 3 and 4. Both the etchants produced good quality color microstructures compared to conventional 
black and white metallography using ferric chloride solution. The contrast is superior to distinguish the alpha and beta phases of the brass. Beraha 13a shows alpha and beta phase in golden yellow and light yellow, respectively. On the other hand, Beraha 12a displays alpha and beta phase in orange and blue violet, respectively. Alpha phase represents copper, while beta phase represents the compound of copper and zinc. The contrast between alpha and beta phase is superior in Fig. 4 compared to Fig. 3. The final color developed depends on the ingredients of the etchants. Two phases respond differently to both the etchants. The development of different colors for the two phases can be attributed to the variation in the thickness of the interference film that is present on the specimen surface. A nanosize thin-film layer is produced on the etched surface after immersion of the sample. In general in color metallography, a change from light color to dark color indicates an increase in the thickness of the interference film [12]. Hence, it can be inferred from the micrographs that the beta phase is less attacked by Beraha 13a compared to Beraha 12a. The thickness of the interference film on beta phase is less in Fig. 3 to that of Fig. 4. Therefore, beta phase exhibits a light color in Fig. 3 and a darker color in Fig. 4. The boundaries of both the phases are delineated clearly which will help to estimate the amount of phases accurately. There is no variation in orange color within alpha phase in Fig. 4. But a variation in blue violet color within the beta phase is observed. This observation indicates that the energy level within the beta phase is unequal. There appears a variation in the stress distribution on the beta phase. Some black spots are seen in Figs. 3 and 4. These black spots represent lead particles. The composition of the brass showed $3.44 \%$ lead as given in Table. It is well known that lead is added to improve the machinability of the brass. The number of black spots in Fig. 3 is higher compared to Fig. 4. This could be possibly by the removal of the lead particles during etching with Beraha 12a. Beraha 12a might have attacked the surrounding brass severely which might have caused the removal of lead particles, while etching is done. The difference in microstructures of various regions within the welded joint is enhanced by the application of color metallography. It helps to extract more information from the micrographs such as stress state and phase identification. In the present work, the micrographs obtained using Beraha 12a etchant are excellent.

\section{Conclusions}

$\mathrm{Cu}-38.55$ brass plates of $6 \mathrm{~mm}$ thickness were successfully welded using FSW, and the microstructures were studied using two different color etchants. The following conclusions are derived from the present work:
- The microstructure of the HAZ was identical to base metal. TMAZ showed a mixture of small and larger size grains. The weld zone consisted of fine equiaxed grains due to dynamic recrystallization.

- A heterogeneous microstructure was observed within the weld zone. The recrystallization process was partial toward the end of the weld zone along the thickness direction.

- The two color etchants revealed the microstructure very clearly. Both the etchants differently colored the alpha and beta phases. The micrographs obtained using Beraha 12a etchant were better than Beraha 13a etchant.

- The dual-phase microstructure was retained in the weld zone which confirmed no loss of zinc during welding.

Acknowledgements The corresponding author is grateful to Dr. N. Murugan, Welding Research Cell at Coimbatore Institute of Technology for his inspiration to pursue color metallography. The authors are also thankful to Mr. A. Vivin Rubusdurai, Mr. K. Kannan, Mr. S. Jeyakumar and Mr. S. Arul Jothii for their assistance.

\section{References}

1. H. Imai, Y. Kosaka, A. Kojima, S. Li, K. Kondoh, J. Umeda, H. Atsumi, Characteristics and machinability of lead-free P/M Cu60-Zn40 brass alloys dispersed with graphite. Powder Technol. 198, 417-421 (2010)

2. C. Meran, M. Yuksel, A. Gulsoz, T. Sekercioglu, The welding problems of thin brass plates and TIG pulse welding. Sci. Technol. Weld. Join. 9, 131-137 (2004)

3. G. Cam, Friction stir welded structural materials: beyond $\mathrm{Al}$ alloys. Int. Mater. Rev. 56, 1-48 (2011)

4. H.S. Park, T. Kimura, T. Murakami, Y. Naganod, K. Nakata, M. Ushio, Microstructures and mechanical properties of friction stir welds of $60 \% \mathrm{Cu}-40 \% \mathrm{Zn}$ copper alloy. Mater. Sci. Eng. A 371, 160-169 (2004)

5. C. Meran, The joint properties of brass plates by friction stir welding. Mater. Des. 27, 719-726 (2006)

6. G. Çam, S. Mistikoglu, M. Pakdil, Microstructural and mechanical characterization of friction stir butt joint welded $63 \% \mathrm{Cu}-$ 37\% Zn brass plate. Weld. J. 88, 225-232 (2009)

7. M.S. Moghaddam, R. Parvizi, M.H. Sabzevar, A. Davoodi, Microstructural and mechanical properties of friction stir welded $\mathrm{Cu}-30 \mathrm{Zn}$ brass alloy at various feed speeds: influence of stir bands. Mater. Des. 32, 2749-2755 (2011)

8. A. Emamikhah, A. Abbasi, A. Atefat, M.K.B. Givi, Effect of tool pin profile on friction stir butt welding of high-zinc brass (CuZn40). Int. J. Adv. Manuf. Technol. 71, 81-90 (2014)

9. N. Xu, R. Ueji, H. Fujii, Enhanced mechanical properties of 70/30 brass joint by rapid cooling friction stir welding. Mater. Sci. Eng. A 610, 132-138 (2014)

10. S. Emami, T. Saeid, Effects of welding and rotational speeds on the microstructure and hardness of friction stir welded singlephase brass. Acta Metall. Sin. 28, 766-771 (2015)

11. H. Zakerinia, A. Kermanpur, A. Najafizadeh, Color metallography a suitable method for characterization of martensite and bainite in multiphase steels. Int. J. Iron Steel Soc. Iran 6, 14-18 (2009) 
12. A.C. Somasekharan, L.E. Murr, Characterization of complex, solid-state flow and mixing in the friction-stir welding (FSW) of aluminum alloy 6061-T6 to magnesium alloy AZ91D using color metallography. J. Mater. Sci. 41, 5365-5370 (2006)

13. E. Beraha, B. Shpigler, Color Metallography (American Society for Metals, Ohio, 1977)
14. G.M. Xie, Z.Y. Ma, L. Geng, Effects of friction stir welding parameters on microstructures and mechanical properties of brass joints. Mater. Trans. 49, 1698-1701 (2008)

15. G.M. Xie, Z.Y. Ma, L. Geng, Partial recrystallization in the nugget zone of friction stir welded dual-phase $\mathrm{Cu}-\mathrm{Zn}$ alloy. Philos. Mag. 89, 1505-1516 (2009) 